\title{
PART II. Major Approaches for Possible Insurance Solutions and their Evaluation
}

\author{
by Dr Juerg Spuehler*
}

\section{Preliminary Remarks ${ }^{1}$}

\subsection{Character of the views expressed}

A suitable starting point for evaluating major approaches in respect of possible insurance solutions for existing hazardous waste facilities is found in the present situation in Europe. Countrywide quite a few alternatives to traditional insurance covers have been established there in the past few years in order to solve or, at least, to ease the problems attached to pollution in general and to waste facilities in particular. Although these alternatives have not fully proved to stand the test of time and have not met all the needs of industrial manufacturers and waste site operators, they represent quite a feasible platform for setting up a general frame for a realistic solution to today's problems discussed hereinafter.

\subsection{The principal role of insurance}

To cope with risks means managing risks. For quite some time very useful instruments have been developed which today reach a state of considerable complexity. They follow the basic line starting from "avoidance" of risks with technical and organizational means and measures, shifting to "suppression" or "reduction" of unavoidable risks with such means and measures, embracing the "transfer" of unavoidable risks which cannot be borne by the risk creator and ending up with "self financing" of residual risks.

This clearly reveals that the function of insurance uniquely consists of transferring the negative consequences of risk from the risk creator to the professional risk carrier. At the same time the general line demonstrates - contrary to public opinion and public expectation - that the existence of insurance does not turn "things" as such into a safe or safer state or to a more acceptable condition at all. Therefore, insurance must not be understood as "the solution in itself" to risk problems in general and to pollution problems in particular. And finally, it must be added to this basic qualification that insurance is not a social compensation system as such!

This paper analyzes in which form such transfer may be accomplished in a reasonable way as far as the risk in respect of pollution resulting from existing hazardous waste sites is concerned.

\footnotetext{
* Swiss Reinsurance Company, Zurich.
} 


\section{Approaches to balance out existing deficiencies for traditional insurance ${ }^{2}$}

First the question arises if it is possible to balance out all or, at least, part of the deficiencies in the requirements in order to enable the transfer of risk attached to hazardous waste facilities by traditional insurance set-ups. Within the range of direct influence by insurers, the primary measures with such an objective are, principally, those of a technical nature focusing on the risk as such and on the shaping of the insurance coverage in a specific way. What is the general situation in respect of these possibilities?

\subsection{Approaches from the risk engineering side ${ }^{3}$}

\subsubsection{Avoidance and suppression or reduction of hazardous waste}

Negative effects on the environment originating from production and distribution processes and from the residues of goods and services after their consumption were, for a very long time, neither disclosed nor considered when taking economic decisions. This situation abruptly changed when the negative effects tending more and more to outweigh the positive side of produced goods and services were recognized on a large scale and became a primary topic in public discussions. The goal of avoiding the negative consequences as such by avoiding the creation of hazardous waste at all is, obviously, unrealistic. We are forced to accept the fact that there will always be hazardous waste of substantial volume and intense toxicity. Therefore, we must look at constructional and organizational approaches in respect of waste sites.

\subsubsection{Constructional and organizational approaches}

Existing facilities do not always match constructional and organizational standards which safeguard the prevention of pollution of the air, the soil and the water in an adequate way - be it for economic reasons (cost-benefit consideration) or due to unknown technical knowledge at the time of establishing the facility. In view of the volume and kind of inherent toxicity most existing sites cannot ex post be fundamentally turned to meet those standards which would be required, at least not within such a period of time to combat the current general situation of danger. There is no other way left than to intensively observe the development of the condition and behavior of such sites around the clock and to interfere in the best possible manner on an emergency basis if the potential risk becomes acute.

The situation described applies to existing facilities. It is - in general - more favorable for "new" facilities, i.e. for facilities which are designed, constructed and operated according to latest standards in respect of drainage, of evaporations, of the kind of waste deposited, of re-cultivating procedures and the like. Furthermore, the kind of deposit is of considerable importance: the more earthcrust-like they are, the safer the waste site regarding the extent of possible environmental impairment, and consequently, the more they qualify to be insured on a traditional basis. However, such deposit sites are only few in number so that the general situation for the insurance issue is not improved significantly by constructional and organizational approaches.

\subsubsection{Conclusions}

Major approaches from the risk engineering side in respect of avoidance and suppression or reduction of the risk originating from hazardous waste facilities are not in a position to offset the deficiencies significantly. This does not, however, mean that operators of waste sites should abstain from applying risk engineering principles. Their extensive and prudent application represents the basic requirement for considering the transfer of risk by insurancelike or insurance-related means as discussed later (cf. 3). 


\subsection{Approaches from the side of available insurance techniques}

\subsubsection{Gradual vs. sudden and accidental}

The confusion in respect of the qualification "gradual" on the one hand and "sudden and accidental" on the other hand exists as ever before (even by disregarding the interpretation that "sudden" is to be understood as "unexpected" and "unintended" which results in affirming the coverage for "gradual" situations). There is no clear understanding of what situation constitutes "gradual" to be undeniably barred from insurance coverage.

Looking at this issue, coverage is to be given when the emission of polluting substances occurs in a sudden and accidental (non-repetitious) way. It is of no importance if - later on - the harmful emission on persons or on property is of a gradual (non-sudden) nature ${ }^{4}$. The reason for this is found in the fact that situations of a sudden and accidental nature are, as a rule, coupled with deviations from the planned and normal running of a manufacturing plant ("breakdown" of plant, machinery and processes). This situation must be honored by underwriters, as it is unexpected and fully recognizable in due time. And therefore the underwriter is able to form the necessary loss reserves early enough.

The present situation in standard wordings for industrial liability policies in the vast majority of European countries corresponds to the mechanism described. Reference is specifically made to the clear wording in the General Conditions for Liability Insurance in Switzerland (Art. 7 f AVB) 5 and in Austria (Art. 6, Pkt. 4.2.1 in connection with Art. 7 , Pkt. 9 AHVB $)^{6}$. In Germany $(4 \text {, Ziff. I./5. AHB })^{7}$ the intention is not plainly expressed, whereas in Denmark the interpretation (not the formulation itself!) of the present ruling implies a very strict cover: emissions as well as immissions must be of a sudden and accidental nature in order to secure coverage. ${ }^{8}$

Turning to hazardous waste facilities, it has to be recognized that the suitability of such an approach in coverage is not established there. It does not meet the specific situation linked to it, and therefore it does not come up to the needs and expectations of facility operators. As a rule, emissions from waste facilities and the immissions resulting therefrom are of a gradual nature. Therefore, the standard insurance technique to handle "gradual" and "sudden and accidental" risk situations in an acceptable way fails in respect to the basic requirements to transfer the risk of hazardous waste facilities from the operator to the insurer by traditional insurance set-ups.

\subsubsection{Unlawful vs. lawful behavior}

In all industrialized countries the emissions -also those of polluting nature - linked with manufacturing processes and plants are allowed up to certain levels as specified in laws and ordinances, and not subject to penal sanctions. Turning to the legal liability side, the question arises whether such emissions leading to harmful effects on persons and property due to their accumulation in the course of time are subject to compensation according to legal liability rules. In addition, there is the question whether a sudden and strictly terminated decrease in the levels of emissions asked for by the authorities turns the former higher immissions therefrom - at the same time as the new ruling takes effect - potentially to legal liability cases. Manufacturers claim that what has been allowed by laws and governmental authorities can never create any liability to pay compensations to third parties. This question has, so far, not been answered clearly.

In general, the accumulations over longer periods of time leading to pollution of the air, the soil and/or the water with negative consequences on persons and property are sub- 
ject to the legal liability rules. Therefore, the way out of the controversy in respect of "gradual" and "sudden and accidental" cannot be found by applying instead the terms and qualifications "unlawful" and "lawful" behavior. As all polluting emissions once falling under "lawful" behavior and the immissions linked to them must be kept away from traditional insurance coverage, the concept of "breakdown of plant, machinery and process" also comes to light again from these views.

Presently, the existing wordings in Industrial Liability Policies used in Switzerland and Germany are rewritten in respect of the pollution coverage contained therein. Thereby the concept of "breakdown" replaces (in Switzerland as per January 1st, 1989), respectively will most probably replace (in Germany) the former concept of "sudden and accidental" in respect of emissions falling under the coverage granted hitherto. The event linked with the "break-down" must be "sudden, unexpected, of a single nature and accidental".

Turning to hazardous waste facilities it is easy to recognize that such an approach does not suit the general purpose and does not meet the inherent situation being present there. Most causes of pollution are not found in a "breakdown" in the sense of the term as mentioned. This fact is responsible for excluding waste sites from the new wordings referred to above; an acceptable solution has, obviously, not yet been found, as the wording for waste sites is left to the individual company willing to underwrite such risks at all, without offering them guidelines by the National Insurance Associations advising their member companies how to proceed.

\subsubsection{The "named perils" approach}

For a few years now, the pollution coverage in Industrial Liability Policies was on a case-by-case basis defined by specifying which perils causing polluting emissions are considered to fall within the scope of cover. The list applied originally contains the following perils: (1) unintended fire, lightning, explosion or implosion and (2) collision or overturning of road (later on: any) vehicles. This approach is strongly related to that of "breakdown of plant, machinery and processes". However, as the span of events triggering the coverage is rather limited, the kind of perils was occasionally extended to "bursting, rupture or explosion of valves, tubes, pipes and the like" thereby leaving the strict path of "sudden and accidental events" and partly turning to "gradual" incidents as such bursts were not defined and specified as those resulting from unique, unexpected, unintentional and accidental mishandling of plants and processes or the like.

\subsubsection{Environmental impairment as target of coverage}

If the air, the soil or the water as "free goods" are disturbed or changed in their "natural" state or condition and, if nature itself is not in a position to balance out or neutralize such an interference within a reasonable time, we are faced with environmental impairment.

As the polluted "free goods" act as carriers spreading their impairment, damage to property as well as injury to persons may result therefrom in addition to the environmental impairment itself.

The question now arises whether the environmental impairment or "only" the consequences therefrom on third party property and persons should be the subject of the insurance coverage. The answer to this very fundamental question cannot be given in an absolute manner. It may be found best in the set-up of the legal liability rules in general or of those referring in particular to environmental impairment. In most countries only specific liability 
rules in respect of water (including ground water) exist today, mostly coupled with the legal obligation of the polluter also to finance prevention as well as clean-up costs related thereto. In addition, such rules focus the compensation in respect of impairment, reduction of and interference with individual rights and amenities protected by law.

From this situation it can be concluded that the subject of the insurance coverage cannot be found along the dividing line "impairment of the free goods" as opposed to the "damaging consequences to third parties resulting from such impairment". The target of the insurance coverage must, therefore, be set within the area fixed by the legal liability rules. In other words, the scope of cover must, in principle, extend to the same impaired media as they are subject to the legal liability rules. This guideline does not, however, quite correspond to the needs of operators of hazardous waste facilities and to the public interest attached to the potential danger resulting therefrom. Taking this into account, some distinction must be made: The protection granted by insurance should also extend to the prevention cost of any contingent damage or injury, even in respect of those which are not subject to compensation according to legal liability rules. It has to be considered that the public interest is focused on keeping the "free goods" unconditionally unimpaired and on taking all possible measures to reverse in the best possible way any impairment which may have occurred.

\subsubsection{Conclusions}

The realized major approaches by the insurance technique are of such a nature that they are not in a position to outweigh the existing deficiencies regarding covers for hazardous waste facilities. An attempt to reword them would hardly be successful without substantially narrowing the protection expected and needed by facility operators.

Thus, the conclusion must be drawn that applying traditional insurance techniques even coupled with suitable risk engineering approaches - fail to adequately cope with the risk situation under review. Modified ways and means must be defined in order to meet the situation. The question arises whether some elements contributing to the accomplishment of this goal can be found in the set-up of specific European insurance programmes in respect of pollution.

\section{Present approaches guiding a modified future solution 9}

\subsection{General remarks}

In 1977 the first significant specific insurance approach was started in Europe to cope with pollution problems. Three other programmes have followed since that time. They do not - with one exception - specifically focus on hazardous waste facilities but on the risk of pollution in general.

\subsection{The GARPOL in France ${ }^{10}$}

The cover provided by GARPOL extends, in principle, to those risks in respect of environmental impairments which are excluded from the French Public Liability Policy. This is the reason why it not only refers to pollution of the soil, the air and the water resulting from the site of industrial activities but also to the negative effects on the neighborhood of such a site due to noise, vibration, odor, radiation and temperature. There is no restriction to sudden and accidental, but the event causing the negative effects covered must be unintended and unforeseen by the insured party. As to the limitation in time, the 
coverage is given, if the damage is manifested and the compensation resulting therefrom is claimed during the policy period. Furthermore, the events covered must be the consequence of facts unknown to the policyholder at the time of inception of the cover. If the policy is not renewed, the claims must be made within one year thereafter on the condition that they are the consequence of events during the policy period. On the other hand, all consequences from the non-observance of legal rules set out in the Special Conditions of the policy are excluded from the cover. It must, however, be pointed out the non-compliance with them only leads to the refusal of coverage if it is the fault of the person responsible for the prevention of pollution.

Subject to a favorable inspection report as basic requirement, coverage is provided for bodily injury and property damage as well as for pure economic loss of third parties resulting from the limitation in making use of specific rights or from the impossibility to render services personally or by real-estates and the like. Furthermore, expenses of the operator to reduce the covered loss, to stop its aggravation or to prevent its realization at all fall within the scope of cover. This extension refers also to the neutralization, isolation and elimination of polluting substances spreading into the atmosphere, the soil or the water if such measures are ordered by law or ordinance.

There are specific provisions in respect of covering closed waste sites. Coverage is given for claims lodged within 5 years after closing of the site (extension in time may be possible).

The Pool capacity presently reaches FF 30 million (= about $\$ 5$ million) per any one event and in the aggregate per any one year whereby the very same kind of pollution is considered as being one single event whether one or more third parties are involved (attempts are made to increase the capacity to FF 100 million in the future). The limit for expenses covered extends to $20 \%$ of the said amount.

By qualifying GARPOL it must be pointed out that it was the first facility in Europe to deal with pollution damage. It inspired the Italian Pool and influenced that set-up extensively. The positive side of GARPOL is found in the fact that it does not distinguish between sudden and accidental or gradual and that it abstains from applying the named perils principle. The aspects of unlawful behavior are quite dominant and constitute explicitly the Special Conditions of the policies by quoting therein numerous laws and ordinances. There is no clear stipulation regarding the consequences in cover for the former but still undiscovered causations and occurrences when such laws and ordinances are changed, thereby restricting the extent of lawful behavior.

\subsection{The Italian "Pool Inquinamento"11}

The Italian Pool, now supported by about 80 direct insurers, started its operations in 1979. It extends to the coverage of environmental impairment of the soil, the air and the water as well as of the negative consequences therefrom on persons and property, regardless of whether they are of a sudden and accidental or gradual nature. Therefore, latency risks fall under the scope of the protection provided. Furthermore, the coverage includes loss of use in the sense of interruption or suspension of industrial, commercial or agricultural activities of third parties. In addition to pollution from the site of the policyholder, there is also coverage for the transportation of hazardous goods available. 
As to the definition in time, the claims made basis has applied since 1988 in order to escape the difficulties in establishing the specific point in time when the pollution was caused or when it occurred.

The present capacity of the Pool is - compared with similar European facilities - rather substantial. It reaches Lit 16 billion (= about $\$ 11$ million) which, if needed, can be extended up to Lit 27 billion by readily available reinsurance. It is the declared objective of the Pool Management to increase the total capacity to Lit 50 billion within the next few years.

The specific Italian set-up demonstrates that there is a real possibility to raise quite substantial financial support for pollution coverage in Europe. Linked with the positive set-up of covering sudden and accidental as well as gradual pollution and of abstaining from the restriction of named perils this facility must be considered as quite progressive. Judging from the qualifications focused in the present view - the aspect of lawful and unlawful behavior in the course of time only remains unsolved.

\subsection{The MAS-Pool in the Netherlands ${ }^{12}$}

Since 1985 potential polluters can obtain cover for sudden and accidental as well as gradual pollution due to lawful behavior by liability insurers registered in the Netherlands through the intermediaries of the MAS-Pool in which more than 50 insurance companies participate. Part C of the Dutch Public Liability Policy which focuses specifically on the environmental risk is subject to the Pool scheme. It covers damage resulting from environmental impairment emanating from the insured's site. Insofar as the damage arises suddenly and unexpectedly, there is an overlap with the standard public liability cover of Part B of the policy; in such a case, Part $\mathrm{C}$ and therefore the MAS-Pool grants, in principle, primary cover.

According to the scheme, environmental impairment in the meaning of the Pool is understood to be the release of any liquid, solid or gaseous material which has an irritating, contaminating, deteriorating or polluting effect in or on the soil, the air or the water (including ground water).

The cover extends to bodily injury and material damage whereby the latter embraces property damage (including polluting or dirtying of objects), pollution or dirtying of water as well as impairment of the economic value of tangible property other than by damage, destruction or loss.

The financial capacity is quite restricted, namely to hfl 5 million (= about $\$ 2.7$ million) per claim. In order to cope with accumulation and the latency character, the indemnity for all claims related to one single impairment or imminent impairment of the environment is restricted to the same amount. And, furthermore, it applies to the maximum coverage per policy within one and the same annual period, too. Thus the indemnity available is rather moderate, although the limitation in time is based on the claims made principle with a retroactive date set at the day of incepting the first policy extending to Part $\mathrm{C}$. In case of cancellation of the policy, there is an irrevocable offer by the insurer to cover the run-off risk for a period of one year.

The cover also extends to salvage-costs which include expenses for measures reasonably taken to avert imminent danger of third parties suffering damage for which the policyholder would be liable and for which the cover provides protection as well as for measures to limit any damage being covered. Clean-up costs are understood to be covered to the 
extent that they have an effect as mentioned. However, there is no explicit coverage for clean-up costs as such at the policyholder's site.

The availability of the protection restricted by limits is linked to a favorable result of the inspection made before inception of the cover. This prerequisite is more and more frequently not accomplished so that no cover can be secured by the industrial entrepreneur requesting it.

All in all, the set-up of the MAS-Pool provides only limited protection to industries. Its major deficiency is found in the very limited financial capacity compared with the dimensions attached to pollution. However, the following positive elements are present: coverage exists for sudden and accidental as well as gradual pollution and there is no restriction to named perils.

\subsection{The Swedish approach ${ }^{13}$}

The Swedish approach falls into two parts: (1) the Environmental Damage Act (since 1986) represents the fundamental basis for specific EIL policies which are coordinated with the pollution coverage provided by ordinary Public Liability Policies; (2) in the near future most probably the Environmental Damage Compensation Fund Bill will be enacted which takes care of the consequences of pollution whose creator is insolvent or not traceable as well as of those which are caused more than 10 years before claiming for compensation (so that they are barred from collecting by the statute of limitation). Both laws do not distinguish between sudden and accidental or gradual pollution, and there is no restriction on the basis of named perils.

The EIL policies provide coverage for gradual pollution up to a limit of about SEK 25 million (= about $\$ 4.3$ million) what constitutes, on average, a far lower amount than that available under Public Liability Policies covering the consequences of pollution of a sudden and accidental nature, only. The specified EIL policy covers bodily injury, property damage as well as economic loss and excludes the consequences of unlawful behavior. Up to now, the demand for such cover has been rather restricted.

The proposed new Act aims at creating a specific fund to finance the cases falling under its provisions. Two alternatives are discussed. One system involves a fixed annual charge that is differentiated by taking into account the influence on the environment and the extent of the operations; it is imposed on most of the plants or activities for which a permit or notification is compulsory. The second aims at charges in relation to the emissions being particularly dangerous for the environment and to the extent of the emission.

The Federation of Swedish Industries, in cooperation with the leading Swedish insurers, favors - as an alternative to the funding system proposed by the Government - a collective insurance system. Such system could take advantage of the insurers' vast experience in managing and preventing environmental losses; therefore it can come into force at short notice; furthermore, an insurance programme is more apt to set the demarcation line between pollution liability insurance of the traditional kind and that by other kinds of insurance referring to environmental damage; in addition, the insurance solution makes the existing risk capital of the carriers available (whereas the other solution would still have to build up such capital over a long time).

The insurance alternative seeks cover limits up to SEK 100 million ( $=$ about $\$ 17.2$ million) for bodily injury and SEK 50 million ( $=$ about 86 million) for property damage with a 
combined annual aggregate of SEK 200 million (= about $\$ 34.5$ million). The limitation in time is based on the principle that all losses are attributed to that year in which the loss or the first of the losses due to the same type of damaging effect is notified to the insurer. It is immaterial whether such loss results from sudden and accidental or gradual emissions or immissions. Furthermore, no exclusion is made for consequences of unlawful behavior of the polluter.

Looking at the perspective in Sweden, there will be an embracing programme for balancing out the financial consequences of pollution. The interaction of the coverage under the Public Liability Policy, the EIL Policy and the new proposed law (be it funding or insurance) is, however, rather complicated - apart from the fact that the limits of indemnity available differ considerably between the different parts.

\subsection{Conclusions}

Although there are quite a few deficiencies in the present specifically pollution-oriented programmes in some European countries, some vital conclusions can be drawn:

Compared with the extent of possible pollution by economic activities the financial capacity is too small; they do not meet the situations to be expected in the near future and, apart from a few exceptions, they do not take into account the specific needs of hazardous waste facilities still in operation. Furthermore, the accumulation of polluting activities within the existing legal barriers as well as the negative consequences of unlawful behavior are not considered, especially not in view of the fact that the line between lawful and unlawful is not uniform at a specific point in time within different geographical areas and not uniform over the period of time as well. Lastly, the coverage provided is strictly focused on third party claims; therefore clean-up costs in the true sense of the term are completely left outside the scope even though such costs may be considerable and thus not be bearable by a possible polluter.

On the positive side, the avoidance of the conflict between sudden/accidental and gradual must be mentioned and the fact that the named perils concept has not been taken up by any of the specific pollution facilities.

\section{Outline for setting new frontiers}

\subsection{The general frame}

New frontiers to solve the present problems attached to hazardous waste facilities can only be realized within a specific frame clearly defined and honored by all parties concerned in the course of time. Such a frame is characterized by the following elements: the kind of sites eligible for the new frontiers, the characteristics of eligible sites being material to the setting of new frontiers, the general needs and expectations of the facility operator and the general requirements of the insurer as risk-bearing institution.

\subsubsection{Eligible sites}

The line has to be drawn between "existing" sites and "new" sites. The former must fall outside the frame to be defined as they are attached to already ongoing polluting effects which could not be separated in a reasonable and strict way from polluting effects resulting from future activities. Even the unknown extent of the already set situation is to be placed outside the frame in order to establish a clear line. "New" sites are equivalent to sites which in construction and operation match up-to-date standards and do not just stand in line with 
minimum governmental requirements but take into account the techniques available today. Thereby the kind of waste deposited as well as its chemical and physical condition is of decisive importance. The closer the material to the earthcrust-like condition, the further back a waste facility can be qualified as "new" in order to be eligible for the "new frontier".

Eligible for the programme outlined below are not only sites of commercially managed facility operators but also those of manufacturing companies. ${ }^{14}$

\subsubsection{Major characteristics of eligible sites}

The characteristics of eligible sites are material to the building up of the new frontier. The primary characteristic to be taken into account is the expected active life-span (= period of time over which the material can be delivered and deposited) of the facility whereby some differentiation between the planned life-span on the one hand and the possible real span of shorter duration in view of possible deficiencies which might crop up later on must be made on the other hand. Material to the set-up of the new frontier must be the most probable worst situation as can be judged at the inception of the risk-bearing setup of the new frontier type.

Secondly, the post-life situation must be taken into account for the assessment of eligibility. It has to be realized that there is a substantial probability that sooner or later a situation may arise on the site itself or in the environment which could call for remedial action (for example clean-up and re-construction in respect of the site itself) or compensation payments regarding property damage or bodily injury of third parties. Depending on the construction, former operation, guarding after close-down and the kind of deposited material the propensity to such actions and compensation is more or less severe.

Furthermore, the flows of "income" and of "outgo" as well as their incongruence as to amount and period of time are material for setting new frontiers. The higher and the earlier the income compared with the situation in respect of the outgo, the more favorable the starting point for setting new frontiers.

\subsubsection{General needs and expectations of the operator}

The needs and expectations of the operator are very extensive. They extend to transfer the financial consequences resulting from own damages including restoration and clean-up costs at the site (= first party loss) as well as those resulting from third party damages and injuries. Thereby the yardstick in respect of financing such consequences must be the actual as well as the future legal rules of any kind and nature. The development of the applicable technical standards must be immaterial. Furthermore, legal liability rules should be left out as single yardstick whether compensation is due or not. Just the fact that financial means are needed to outweigh own or third party expenditures should be the guideline for setting-up of new frontiers. By applying this general approach the possible twisting in the interpretation of terms, legal rules, origins of impairments and the like can be avoided. Thus, for example, it is immaterial whether the negative polluting effects are of a sudden and accidental or gradual nature. And furthermore, the criteria applied within the named perils approach can be skipped. Lastly, the limitation of own financial means on the operator's side must be taken into account, primarily with a view to the flows of income and outgo (in time as well as in amount).

\subsubsection{General requirement of the insurer}

The role of the insurer as bearer of the risk transferred to him is, in general, limited by two requirements: there must be a limitation of his engagements in amount and in time. 
Otherwise the transfer and the mix of different origins of risk do not meet his own general position which is characterized by a limitation of financial means, manpower and knowhow. Finally, a fair chance to secure an adequate surplus in the course of time must be safeguarded.

\subsubsection{Bridging the positions of the primary parties involved}

The facility operator as risk creator and the insurer as bearer of the transferred risk are the primary parties involved. Their needs, expectations and requirements are, to a considerable extent, opposed to each other. The possibility to set new frontiers requires therefore the bridging of the two standpoints. The past has shown that such bridging was not accomplished as the economic chances on each side were not safeguarded in the course of time, primarily due to changed and twisted legal frames as well as to imperfect technical knowledge. As in future these threats cannot be eliminated, the new frontiers must as much as possible be made independent of them and primarily focus on the financial needs resulting aperiodically from the facility operations.

\subsection{Outline of a solution: first view}

In the first place the general set-up and the financial approach is outlined in order to demonstrate the fundamental mechanism of the programme setting new frontiers.

\subsubsection{Set-up of a Liability Life Policy $(L L P)^{15}$}

When opening up a hazardous waste facility, one fact must be taken into account: sooner or later most probably first or third party losses will arise and compensation payments will become due. Therefore, there is the fundamental need to secure their financing by a specific programme which adequately takes care of such a situation. In addition, there is the contingency in respect of the point in time when such losses or costs must be met. Furthermore, the length of time over which the adequate prefinancing can be accomplished is not known in advance at the time the waste facility is opened. It may well be that after a relatively short period of time - due, for example, to inadequate depositing activities or misinterpreted geological surveys - the facility must be closed long before the envisaged capacity has been used up. Then, the facility operator has no income any longer, even though after that point in time substantial financial means must be at hand in order to cope with possible clean-up and environmental impairment.

The programme to meet all the requirements resulting from this general situation may be found best in the form of a Liability Life Policy. The term "liability" signifies on the one hand that it takes care of third party claims based on legal liability rules and, on the other hand, that the first party expenses imposed on the facility operator by law and specific requirements established by the licensing authorities are taken into account. The term "life" is intended to demonstrate that the programme aims at working during the whole life-span of a hazardous waste facility, embracing also the time after its closing (even though more or less limited). And the term "policy" is used, as the risk transfer shall be contracted by an insurance-like policy through a traditional insurance carrier. The capitals of the three terms used then end up in the abbreviated denomination "LLP".

\subsubsection{Financial approach}

In line with the opening of a "new" hazardous waste facility fundamental investments are necessary. Part of them fall under the set-up of LLP in the form of an initial lump sum payment (pay-down investment). Such payment constitutes the primary financing of 
compensations accruing in the course of the time for first and third party claims. The initial lump sum payment is increased by periodical (as a rule annual) payments the extent of which must stand in line with the degree of risk set by the deposits of the same period.

In the course of time, the pay-down investment and the periodical payments - both reduced by the risk bearer's own cost and profit margin and the risk part counterbalancing payments for possible premature first and third party claims - add up to a fund which is increased by the net interest earned on it. The risk bearer guarantees at any time during the period for which the programme runs an agreed maximum amount for the payment of first and third party compensations falling due. As long and as far as the guaranteed limit exceeds the fund accrued, the risk bearer has to pay the difference out of his own assets primarily financed by the risk part of the initial and periodical payments under LLPs.

In principle, the programme aims at raising the necessary financial means over the period of time itself. However, at any time gaps may exist and - depending on the extent and frequency of payments for damage, injury, clean-up costs and the like-change their extent. The contingent amounts resulting from such gaps constitute the risk part (contrary to the financial part) of the scheme and thus represent the insurance-related element borne by the risk carrier. Furthermore, the activity of the risk carrier consists of the assessment of the facility at the beginning of the programme, of permanent servicing and supervising the facility during its whole life-span, of rendering technical support to the facility operator, of taking care of claims made against the facility operator and of investing the funds accrued. Though the basic idea originates from the mechanism of a mixed life insurance policy, the contractual services of the risk carrier go far beyond those attached to such a policy.

As from the point in time when the facility is closed there will be no income to the facility operator any longer. Consequently there are no further periodical payments to be made under the programme. The only financing sources left are those from net interest resulting from the fund accrued.

It is a question to be discussed for what period the programme is supposed to run; however, the programme is focused on a long-term duration. Various alternatives are at hand. There may be a pre-fixed period of time (including also part of the time after the planned closedown of the facility) or an agreement according to which the programme is to run until the unknown contingent date of effectively closing the facility (with a subalternative which extends the expiry date of the programme to a definite pre-agreed number of years after the unknown contingent closing date). In order to balance out the risk and the chances of both parties involved in the LLP, the programme should, as a principle, be unredeemable. Or, as a possible alternative, there is the firm obligation of the facility operator to immediately pay the discounted total of all periodical payments still outstanding if he withdraws from the programme prior to the ordinary termination. Such barrier is necessary to make the cancellation unattractive, above all in those cases where at a specific moment there is a considerable gap between the total of the payments already made and the compensation for first and/or third party losses being due. Thus, it is possible to allow for cancellation by either of the two parties. In such a case, the cancellation terms must be of such a kind that they are to the disadvantage for the withdrawing party.

Finally there is the question to whom the amount accrued at expiry of the programme belongs to, if there is any left. In principle, such amount belongs to the facility operator as he financed it primarily. On the other hand, the carrier to whom the contingent risks are 
transferred should - as a super-margin - participate partly on such accrued amount as there is a substantial possibility that at the end of the period during which the programme was in force, there is a deficit which falls completely to the burden of the insurer.

The LLP corresponds to the general requirements of the insurer. There is a limitation of engagement in amount, namely the guaranteed maximum of total compensations to be paid. And there is a limitation of engagement in time though not always stipulated by a specific pre-determined number of years; but there is definitely no open-end in time as to the obligation of the insurer to pay compensations within the agreed scope of the scheme.

\subsection{Outline of a solution: second view}

The first view taken on the outline of a solution must be defined more precisely as to necessary differentiations in determining the contributions from the facility operator and as to the kind of possible incentives for his benefit.

\subsubsection{Differentiation of contribution}

Obviously the contributions from the facility operator (amount of the pay-down investment and periodical payments) depend on the period for which the programme is concluded in relation to the total life-span of the facility as planned and expected according to the assessment done. In combination with the guaranteed maximum of total compensations from the insurer these two contributory components can be calculated. In order to escape the possible burden resulting from substantial changes in the rate of interest over long periods of time, the institution of zero bonds may be used; by approaching on these grounds the calculation of accruing interest is eased.

However, in relation to hazardous waste facilities a very dominant aspect must be observed which may outrule all the considerations made in respect of the financing as mentioned. These are the incentives for the risk creator to be incorporated in the programme.

\subsubsection{Kind of incentives and their evaluation}

The incentives which qualify for application must be of such a nature that they substantially contribute to make the hazardous waste facility and the operational activities resulting therefrom safer. Therefore, the incentives must already be attached to the very first decision taken by an operator, namely the determination of the site's location and the layout of all the installations and operational procedures. The risk carrier is to be involved from the beginning in order to bring in all his past experience with handling and depositing hazardous waste. The earlier and the more intensive his involvement, the more substantial the incentives offered. Such incentives are reflected in the amount of the guaranteed limit, the relation of that amount to the amount of the pay-down investment, the minimum periodical amounts to be paid and the period of time during which the programme is to run. The more favorable the early involvement, the higher the amount of the guaranteed limit, the smaller the pay-down investment in relative terms, the smaller the minimum periodical amounts to be paid and the longer the period during which the programme is to run.

The same effects may originate from the kind of waste to be deposited as well as its state and condition at the time of deposition. The more the waste deposited is of an earthcrust-like state and condition the more favorable the programme can be set-up.

Finally, it must be mentioned that each and every payment for first and third party losses increases, according to a predetermined schedule, the future periodical payments to 
be made by the facility operator whereas claims free periods of twelve months initiate a rebate standing in line with the schedule mentioned (bonus/malus system according to a pre-fixed schedule).

These aspects demonstrate clearly that the embracing assessment by experts is the fundamental prerequisite for realizing the solution outlined. Furthermore, strong incentives must be built in. They assure that the facility operator and the risk carrier are partners and not opponents.

\subsection{Outline of a solution: third view}

Finally, the outline of a solution must be defined more precisely in respect of the qualification "new" site and the determination of the earliest inception of coverage under the LLP programme.

Also those sites are qualified for the scheme which are already in operation, provided that they correspond to the requirements for being "new" as referred to earlier. In all these cases backward-cover should be obtainable from the original start of the facility operations. Such cover must, however, be tied to the exclusion of all those facts known at the time of incepting the backward-cover which presumably may give rise to compensations later on. Furthermore, for its establishing a lump sum must be paid which amounts to the total of those contributions which otherwise accrued since the opening of that facility.

In such a way the extent of application of the LLP can be appropriately expanded.

\section{Final conclusions}

The presented outline for a solution setting new frontiers can only be realized when the "playing rules" embodied in the original objectives and mutual agreements between the parties are honored over the course of time. Let us hope that - by recognizing the urgent need solving the problems now and speedily in respect of "new" hazardous waste facilities - this will be the case so that the present generation meets its far-reaching obligation for the benefit of the future generations what hazardous waste facilities are concerned. 


\section{REFERENCES}

1) The views expressed in this paper must be understood as a contribution to the discussion focusing on new frontiers in managing hazardous waste facilities. They do not represent a commitment for Swiss Re to offer appropriate capacity as such and unconditionally in respect of the "Outline for setting new frontiers" (cf. 3).

2) see Appendix 1

3) McCann, Patrick G.: Waste Minimization and Recycling Options, in: Hazardous Materials and Waste Management Magazine, May - June 1987.

4) Example as illustration: Due to a handling error the pressure in a tube containing toxic substance is increased to such an extent that the tube bursts (qualification for "sudden and accidental" being present). The toxic substance is pressed high in the air where it evaporates to a considerable degree and, in turn, spreads gradually over a vast area around the location of the production plant. In the course of time the evaporated toxic substance falls upon persons and property in that area causing step by step (this is "gradually") injury and damage to them.

5) Current edition of the General Conditions which will be altered by January 1, 1989: "Von der Versicherung ausgeschlossen sind: ..., die Haftpflicht für Schäden an Sachen durch allgemeine Einwirkung von Witterung, Temperatur, Rauch, Staub, Russ, Gasen, Dämpfen oder Erschütterungen, ausser wenn die allmähliche Einwirkung auf ein plötzlich eingetretenes, unvorhergesehenes Ereignis zurückzuführen ist."

6) "Versicherungsschutz für Schäden durch Verunreinigung von Erdreich und Gewässern: Der Versicherungsschutz bezieht sich auf Sach- und reine Vermögensschäden - einschliesslich des Schadens an Erdreich und an Gewässern -, die Folge einer vom ordnungsgemässen, störungsfreien Betriebsgeschehen abweichenden, plötzlichen Ursache sind, auch wenn diese Schäden allmählich eintreten. Insoweit ist Art. 7, Pkt. 9 nicht anzuwenden."

7) Ausschlüsse (current edition): "Haftungsansprüche aus Sachschaden, welcher entsteht durch allmähliche Einwirkung der Temperatur, von Gasen, Dämpfen oder Feuchtigkeit, von Niederschlägen (Rauch, Russ, Staub, u. dgl.), ferner ..."

8) "The insurance shall only cover liability for claims arising out of pollution or contamination to or through air, soil or water in consequence of the operation of the business of the insured, its waste dumps or its removal or waste production, surplus production or scrap production as well as any injury to persons or damage to property occurring in the course thereof, insofar as any such injury or damage occurs unexpectedly, unintentionally and accidentally ...".

9) see Appendix 2

10) Deprimoz, J.: Les garanties Garpol et les perspectives de couverture en Europe, dans: L'assurance Francaise, 15 - 31 decembre 1987, pp. 908 - 912.

11) Bernardi, Alfredo: Il mercato assicurativo italiano di fronte ai rischi da inquinamento, Convegno "Il Danno Ambientale, Regolamentazione, Prevenzione, Sicurezza", ANIA, 30.11.1987.Piace a pochi il grande Pool, nel: Giornale delle assicurazioni, N. 87, Gennaio 1988.

12) Wansink, John H.: The New Environmental Impairment Liability Insurance (undated manuscript).

13) Swedish Government Official Report, SOU 1987:15. Mid of June 1988 the Swedish Parliament has approved the insurance solution coming into force by July 1, 1989.

14) According to recent statements made by experts in current discussions, $96 \%$ of the total waste is deposited at sites belonging to manufacturing companies and only $4 \%$ in commercially operated facilities.

15) see Appendix 3 


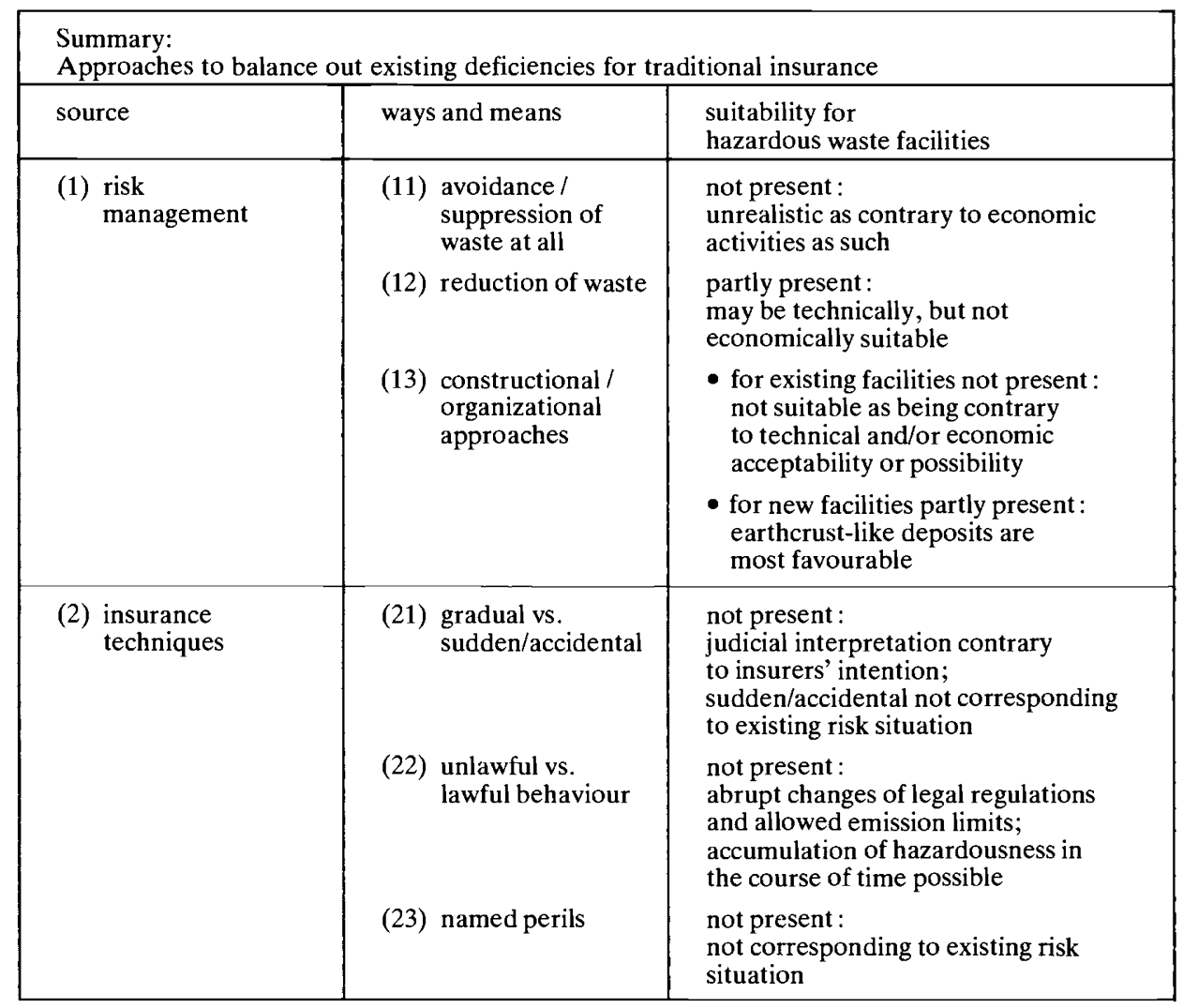

\section{APPENDIX 2}

\begin{tabular}{|c|c|c|c|}
\hline \multicolumn{4}{|c|}{$\begin{array}{l}\text { Summary: } \\
\text { Major European approaches on pollution coverage }\end{array}$} \\
\hline \multicolumn{2}{|c|}{ country/facility } & \multirow{2}{*}{$\begin{array}{l}\text { capacity } \\
\text { FF } 28 \text { million (maximum) } \\
(=\text { about } \$ 5 \text { million })\end{array}$} & \multirow{2}{*}{$\begin{array}{l}\text { principal coverage } \\
\text { sudden/accidental } \\
\text { as well as gradual pollution due to } \\
\text { lawful behaviour; } \\
\text { no restrictions to named perils }\end{array}$} \\
\hline & $\begin{array}{l}\text { France: } \\
\text { GARPOL } \\
\text { (since) }\end{array}$ & & \\
\hline (2) & $\begin{array}{l}\text { Italy: } \\
\text { Pool Inquinamento } \\
\text { (since 1979) }\end{array}$ & $\begin{array}{l}\text { Lit } 16 \text { billion } \\
(=\text { about } \$ 11 \text { million) } \\
\text { (including reinsurance } \\
\text { capacity: up to } \\
\text { Lit } 27 \text { billion) } \\
\text { per any one event }\end{array}$ & $\begin{array}{l}\text { sudden/accidental } \\
\text { as well as gradual pollution due to } \\
\text { lawful behaviour; } \\
\text { no restruction to named perils }\end{array}$ \\
\hline
\end{tabular}




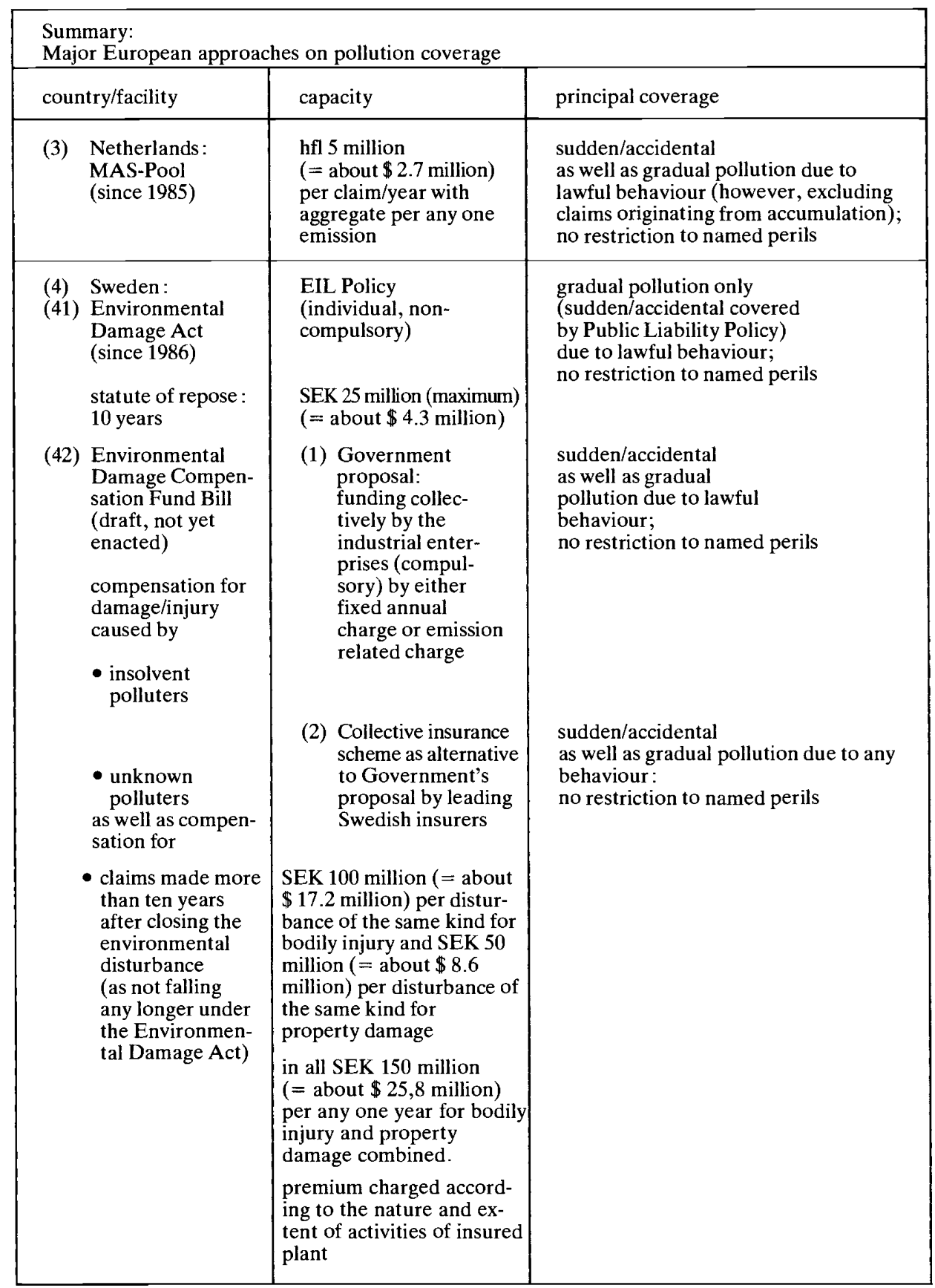




\section{APPENDIX 3}

\section{Mechanism of the Liability Life Policy (LLP)}

maximum of total compensation to be paid

\section{lump sum} payment at inception as part of the total starting investment for the facility

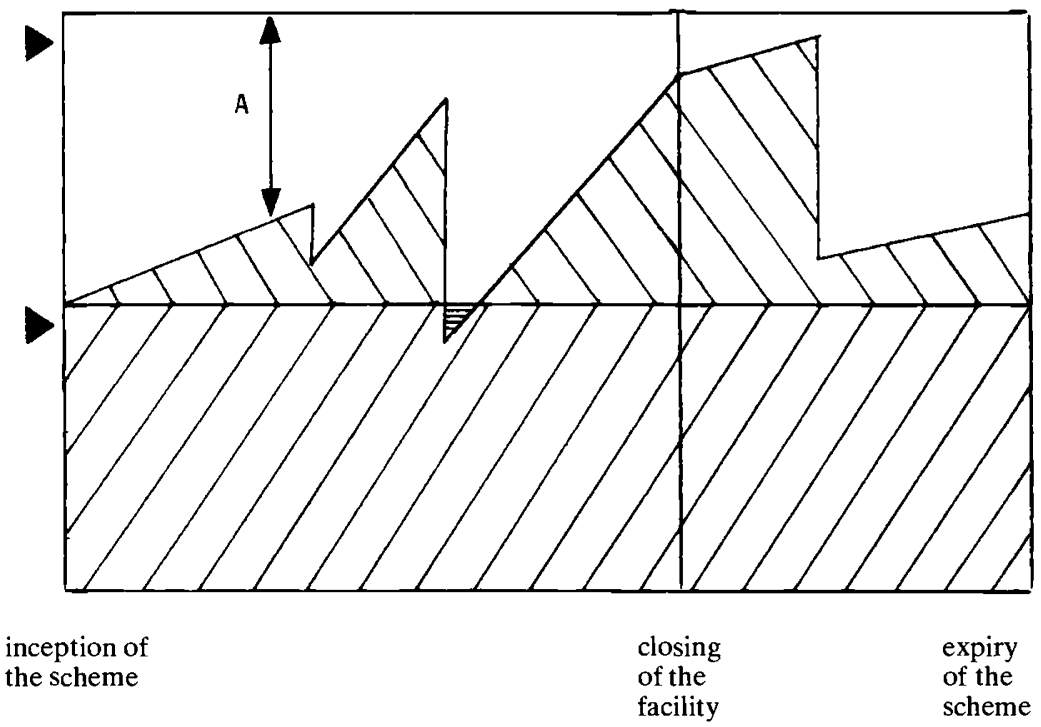

"amount at risk" for the risk carrier at that point in time

"lump sum" (pay-down investment) at inception

"accumulated sum" resulting (1) from the net interest on the unused capital amount (surplus) and (2) from periodical payments by the operator

possible situation where the "accumulated sum" is exceeded by the "compensation payments" 